Bidik: Jurnal Pengabdian kepada Masyarakat | Vol. 2 No. 1 Oktober 2021

\title{
Peningkatan Kemampuan Pustakawan dan Pemuda Kampung Sialang Sakti Melalui Pelatihan Pengolahan Limbah
}

\author{
Triono Dul Hakim*, Syahdan, Azlin Atika Putri \\ Prodi Ilmu Perpustakaan, Fakultas Ilmu Budaya, Universitas Lancang Kuning \\ *Email : trio@unilak.ac.id
}

\begin{abstract}
This service activity aims to provide training on the use of economic value waste to librarians and youth of Siak Sakti village, Siak. This is a continuation of the previous program that has been running, namely screen printing training to provide an alternative source of income for the youth of Sialang Sakti village who have several limitations so that they cannot continue their education to college due to economic factors. Therefore, it is necessary to make efforts to maximize the potential of the area, for example the village library. Sialang Sakti Village already has a Bina Ilmu village library which has been trusted as an inclusive library so that it has the opportunity to empower the community around the village. The target of this activity is to provide skills for librarians to process waste to add to the aesthetics of the library space and advanced screen printing training to the youth of Sialang Sakti village. The output produced is that librarians are able to process various wastes to improve the aesthetic appearance of the library space and the skills of youth to create a creative economy that is being developed by the Government of the Republic of Indonesia. This activity is a collaboration between a team of service lecturers who have expertise in the use of waste-based learning media and experts in screen printing.
\end{abstract}

Keywords: Inclusive Libraries, Waste Utilization, Library Space Aesthetics, Creative Economy

\begin{abstract}
Abstrak
Kegiatan pengabdian ini bertujuan untuk memberikan pelatihan pemanfaatan limbah bernilai ekonomi kepada pustakawan dan pemuda kampung sialang sakti, Siak. Ini merupakan lanjutan dari program sebelumnya yang telah berjalan yakni pelatihan penyablonan untuk memberikan alternatif sumber penghasilan pemuda kampung Sialang Sakti yang memiliki beberapa keterbatasan sehingga tidak dapat melanjutkan pendidikan ke perguruan tinggi disebabkan faktor ekonomi. Oleh karena itu perlu dilakukan upaya untuk memaksimalkan potensi yang dimiliki wilayah tersebut, misalnya perpustakaan desa. Kampung Sialang Sakti telah memiliki perpustakaan desa Bina Ilmu yang telah dipercaya sebagai perpustakaan inklusi sehingga memiliki peluang untuk dapat memberdayakan masyarakat sekitar desa. Target kegiatan ini memberi keterampilan kepada pustakawan melakukan pengolahan limbah untuk menambah estetika ruang perpustakaan dan pelatihan penyablonan tingkat lanjut kepada pemuda kampung Sialang Sakti. Luaran yang dihasilkan adalah pustakawan mampu mengolah berbagai limbah untuk meningkatkan tampilan estetika ruang perpustakaan dan keterampilan pemuda untuk menciptakan ekonomi kreatif yang tengah dikembangkan oleh
\end{abstract}


Pemerintah Republik Indonesia. Kegiatan ini merupakan kolaborasi antara tim dosen pengabdian yang memiliki keahlian dalam penggunaan media pembelajaran berbasis limbah dan tenaga ahli dalam penyablonan.

Kata kunci : Perpustakaan Inklusi, Pemanfaatan Limbah, Estetika Ruang Perpustakaan, Ekonomi Kreatif

\section{Pendahuluan}

\section{Analisis Situasi}

Persoalan sampah masih menjadi salah satu perhatian serius pemerintah. Hasil riset Sustainable Waste Indonesia (SWI) menunjukkan bahwa sekitar 24 persen sampah di negeri ini masih belum terkelola dengan baik. Artinya ada sekitar 65 juta ton sampah diproduksi tiap hari, dimana sekitar 15 juta ton akan mengotori ekosistem dan lingkungan karena tidak ditangani dengan baik. Hanya sekitar 69 persen sampah saja yang sampai ke Tempat Pembuangan Akhir (TPA), dan hanya 7 persen sampah yang didaur ulang. Dari hasil riset ini juga terungkap bahwa sampah organik mendominasi sebanyak 60 persen, disusul sampah plastik sebanyak 14 persen, sampah kertas 9 persen, metal 4,3 persen, kaca, kayu dan bahan lainnya sebanyak 12,7 persen (Indonesia, 2018).

Permasalahan limbah ini tentunya harus ditangani bersama antara Pemerintah Daerah dan masyarakat. Terlebih lagi pemanfaatan limbah rumah tangga, merupakan bagian yang tidak terpisahkan dari aksi mitigasi dan adaptasi perubahan iklim, dan menjadi bagian penting dari program kampung iklim di tingkat tapak (Afni et al., 2021). Keterlibatan masyarakat sangat penting dalam pengelolaan limbah dimulai dari tingkat rumah tangga. Selain itu diperlukan kolaborasi dan koordinasi para pihak di semua tingkatan sosial dan pemerintahan untuk mengatasi persoalan limbah agar tidak merugikan kehidupan masyarakat secara keseluruhan (Krisnawansyah et al., 2018).

Persoalan sampah yang terjadi di daerah tentu tidak terlepas dari masih rendahnya perilaku hidup bersih dan sehat yang ada di masyarakat. Semua persoalan ini tentu saja perlu menjadi perhatian serius, jika ingin menciptakan lingkungan yang berkualitas. Karena itu selain mekanisme pengelolaan sampah, juga sangat penting untuk melibatkan partisipasi masyarakat. Beberapa contoh sudah ditunjukkan oleh beberapa daerah di Indonesia, diantaranya dengan membuat bank sampah, mendaur ulang sampah menjadi produk baru, dan berbagai teknologi dan inovasi lainnya (Mustaghfiroh et al., 2020).

Menghilangkan perilaku masyarakat dalam membuang limbah memang tidak mudah. Oleh karena itu, hal yang dapat dilakukan adalah alteration yakni mengalihkan suatu kebiasaan kepada perbuatan lain yang bermanfaat untuk dirinya. Misalnya, perbuatan membuang limbah sembarangan dapat dialihkan dengan mengelompokkan jenis limbah dan mengolahnya menjadi kompos dan barang kerajinan tangan. Disebagian wilayah perkotaan di Indonesia, kegiatan pengolahan limbah menjadi barang kerajinan tangan sudah mulai berkembang beberapa waktu terakhir. Kegiatan ini tentunya tidak hanya positif dari aspek pembuangan limbah sembarangan, tetapi juga dapat memberikan nilai tambah bagi pelaku kegiatan.

Kampung Sialang Sakti merupakan salah satu desa di wilayah Kecamatan Dayun Kabupaten Siak. Secara demografi, mayoritas penduduk diwilayah ini berprofesi sebagai petani petani 
penggarap. Sebagian lainnya adalah karyawan perusahaan perkebunan sawit dan pemilik lahan kebun sawit. Sebagai wilayah yang berada ditengah perusahaan perkebunan sawit (PTPN V), mayoritas populasi Kampung Sialang Sakti adalah kaum muda ( $\leq 40$ tahun) dan memiliki pendidikan rata-rata SMP dan SMA. Hanya sebagian kecil masyarakat yang mampu melanjutkan pendidikan hingga ke perguruan tinggi karena faktor ekonomi, khususnya bagi anak petani penggarap lahan sawit.

Secara rerata, Kampung Sialang Sakti merupakan wilayah yang relatif maju di Kabupaten Siak dan telah memiliki beberapa fasilitas kesehatan dan pendidikan yang baik. Wilayah ini juga memiliki Perpustakaan Inklusi Bina Ilmu dan merupakan salah satu percontohan perpustakaan desa di Propinsi Riau. Perpustakaan Inklusi ini telah berperan penting dalam pemberdayaan masyarakat, baik untuk meningkatkan literasi maupun kebutuhan pengembangan ekonomi masyarakatnya.

Semakin bertambahnya populasi kaum muda dan keterbatasan pilihan pekerjaan di Kampung Sialang Sakti dikhawatirkan dapat berdampak terhadap pertumbuhan angka pengangguran. Untuk itu generasi muda memerlukan pendampingan agar bisa memanfaatkan kemajuan teknologi untuk melakukan kegiatan yang lebih bermanfaat bagi meningkatkan kualitas hidup masyarakat (Candrasari et al., 2020).

Selain itu, pengetahuan terhadap pemanfaatan limbah rumah tangga untuk kebutuhan kerajinan tangan juga masih sangat terbatas. Oleh karena itu, pemerintah desa dapat memanfaatkan keberadaan perpustakaan inklusi dalam memfasilitasi berbagai kegiatan yang dapat mengurangi dampak yang ditimbulkan oleh pertumbuhan pengangguran dan pertambahan jumlah limbah rumah tangga tersebut.

Perpustakaan Inklusi Bina Ilmu dapat bergerak memberdayakan pemuda kampung yang ada disekitar lokasi perpustakaan. Terlebih lagi karena perpustakaan telah bertransformasi berbasis inklusi sosial, dan ini telah menjadi salah satu kebijakan prioritas pemerintah. Tujuannya agar pustakawan dapat melakukan penguatan literasi, sehingga dapat meningkatkan kesejahteraan masyarakat sekitar (Prasyesti, 2021). Adapun yang menjadi tujuan dari pelatihan ini adalah:

- Melatih pustakawan untuk memanfaatkan berbagai limbah untuk meningkatkan estetika ruang perpustakaan

- Melatih kaum muda untuk mengenalkan berbagai kerajinan tangan yang bersumber dari limbah

- Melatih kaum muda untuk memiliki keahlian sebagai sumber penghasilan, seperti sablon.

- Membantu perekonomian masyarakat

\section{Permasalahan Mitra}

Permasalahan umum pihak mitra yakni keterbatasan pemanfaatan limbah untuk meningkatkan estetika ruang perpustakaan pada perpustakaan inklusi dan masih banyaknya pemuda Kampung Sialang yang belum memiliki pekerjaan tetap, khususnya pada masa penanaman ulang kebun sawit sehingga berdampak pada sumber penghasilan dan ekonomi keluarga. Selain itu Pustakawan belum mampu memaksimalkan limbah yang dihasilkan perpustakaan dan atau rumah tangga untuk dibuat menjadi kerajinan tangan yang menambah estetika ruang perpustakaan. 


\section{Pedekatan Pelaksanaan Program}

Pengabdian ini dilaksanakan dengan memberikan pelatihan kepada pustakawan untuk memanfaatkan limbah perpustakaan dan atau limbah rumah tangga untuk dijadikan hiasan ruang perpustakaan. Selain itu kegiatan ini memberikan bimbingan kepada pustakawan agar dapat melatih dan memberdayakan kaum muda disekitar perpustakaan untuk mengolah limbah rumah tangga sebagai kerajinan yang bernilai ekonomis. Pada kegiatan ini juga diberikan pelatihan penyablonan kepada pemuda Sialang Sakti untuk memiliki keahlian penyablonan sebagai tindak lanjut dari kegiatan pengabdian sebelumnya.

Adapun alur kegiatan dimulai dari persiapan dengan melakukan studi literatur dan koordinasi dengan instansi terkait pra kegiatan, kunjungan ke lokasi kegiatan untuk melakukan perancangan materi pengabdian, pelaksanaan kegiatan, dan hasil kegiatan pengabdian. Adapun yang menjadi ukuran keberhasilan kegiatan yakni 1) Terwujudnya kerja sama antara pelaksana kegiatan dengan pihak Perpustakaan Desa Bina Ilmu Sialang Sakti, 2) Jumlah peserta yang hadir minimal 50\% dari undangan, 3) Adanya interaksi dua arah dalam kegiatan antara pembicara dan peserta, 4) Meningkatnya pengetahuan peserta terkait dengan materi yang disampaikannya, 5) Peningkatan pengetahuan peserta kegiatan diukur dengan penyebaran kuesioner sebelum dan sesudah kegiatan.

\section{Pelaksanaan Program}

Kegiatan pengabdian ini telah dilaksanakan pada tanggal 1 Juli 2021 bertempat Perpustakaan Sialang Sakti, Siak Sri Indrapura. Hadir dalam kegiatan pustakawan, kelompok pemuda desa, dan tokoh masyarakat. Dalam satu hari pelaksanaan kegiatan dibagi dalam beberapa sesi.

Sebelum sesi pertama dimulai, tim pelaksana memberikan lembar kuesioner (angket) kepada setiap peserta untuk mengetahui apakah pustakawan dan pemuda kampung sialang sakti sudah pernah melakukan pelatihan pengolahan limbah.

Dilanjutkan pada sesi kedua, narasumber dari tim pengabdian dan tim ahli memberikan meteri untuk meningkatkan pemahaman masyarakat tentang bahaya limbah dan pentingnya pemanfaatan barang-barang bekas. Peserta diberikan kesempatan untuk berdiskusi dan mengemukakan pertanyaan-pertanyaan terkait dengan meteri yang disampaikan. Dalam sesi ini peserta yang hadir sangat antusias, ditunjukkan dengan keaktifan memberikan pertanyaan dan mendapat tanggapan dari narasumber yang hadir. Sesi kedua ini berlangsung selama kurang lebih 2 jam.

Memasuki sesi ketiga peserta diberikan simulasi pembuatan mebel dari botol plastik yang diisi dengan sampah plastik sehingga barang bekas plastik menjadi bernilai ekonomis tinggi. Dari kegiatan ini peserta mendapatkan peningkatan pemahaman dan kemampuan dalam mengelola sisa limbah di sekitar mereka, sehingga bisa diolah menjadi lebih bermanfaat. Foto 1 menunjukkan narasumber saat memberikan pelatihan pemanfaatan limbah pada peserta. 
Gambar 1. Narasumber saat memberikan pelatihan pemanfaatan limbah pada peserta

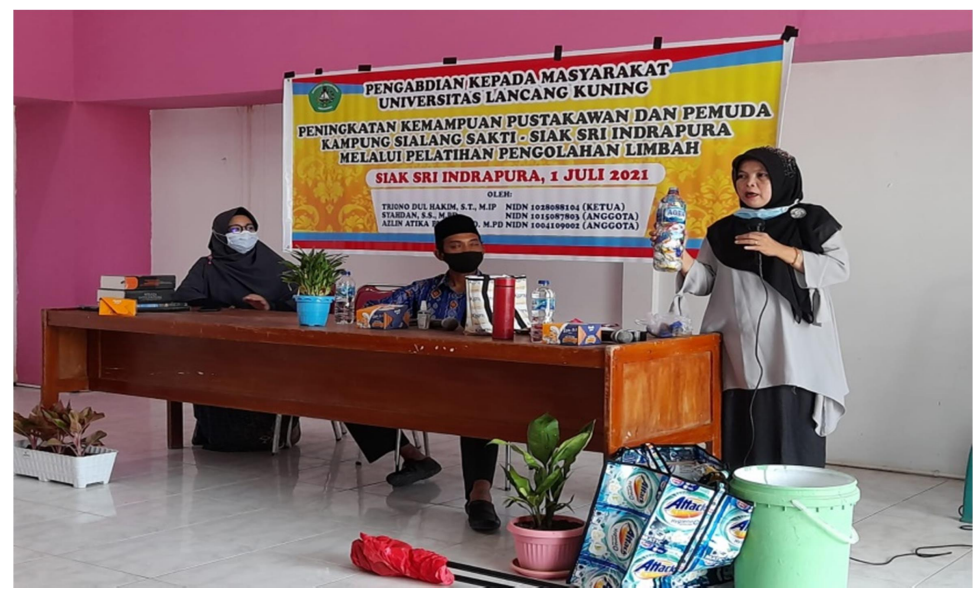

Kegiatan dilanjutkan dengan simulasi pembentukan kelompok bank sampah pada tingkat desa yang dapat berkontribusi terhadap sumber pemasukan bagi desa. Peserta mendapatkan pengetahuan dasar tentang pentingnya keberadaan Bank Sampah, dan manfaat ekonominya bagi lingkungan dan ekonomi masyarakat sekitar. Foto 2 menunjukkan contoh pemanfaatan limbah yang memiliki nilai ekonomi.

Gambar 2. Pemanfaatan limbah plastik menjadi barang yang bernilai ekonomi

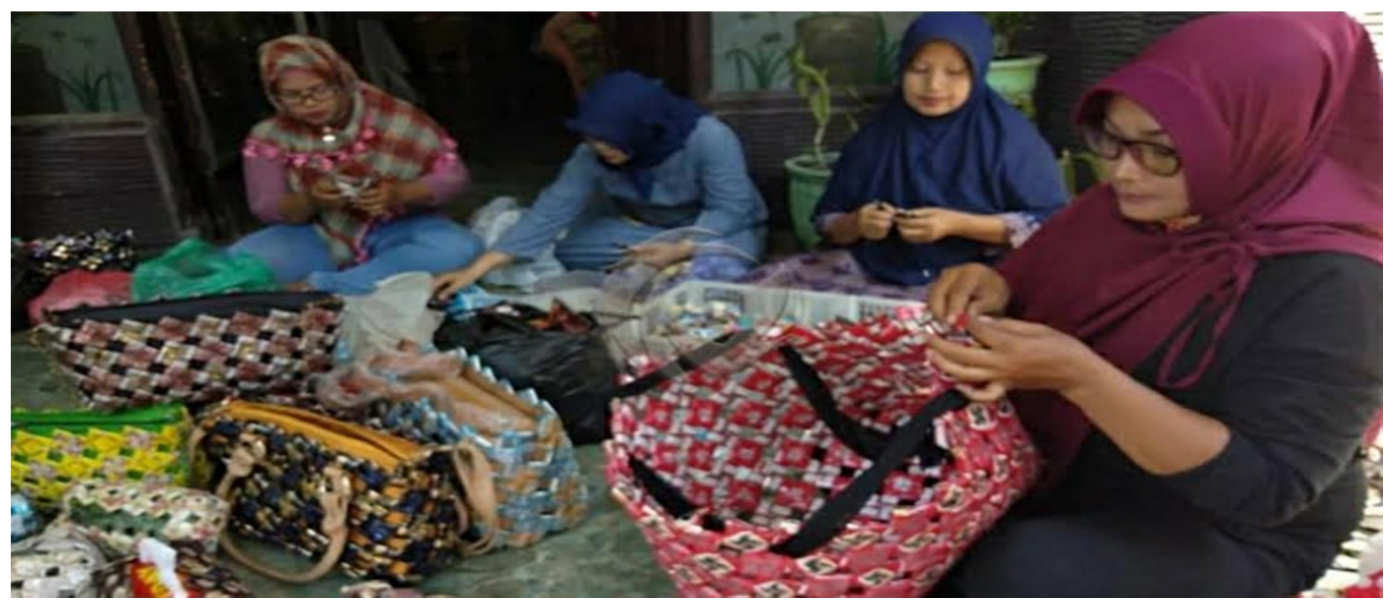

Sebelum menutup sesi terakhir, tim pengabdian memberikan lembar kuesioner (angket) yang bertujuan untuk melihat sejauh mana pemahaman peserta terhadap pelatihan pengolahan limbah. Keseluruhan sesi berlangsung kurang lebih 3 jam. Selama kegiatan ini juga terlaksana diskusi untuk merancang keberlanjutan program bagi kelompok mitra. Diakhir kegiatan juga diberikan sumbangan buku untuk menambah koleksi perpustakaan mitra. Foto 3 menunjukkan interaksi saat kegiatan pengabdian. 
Gambar 3. Interaksi saat kegiatan pengabdian masyarakat

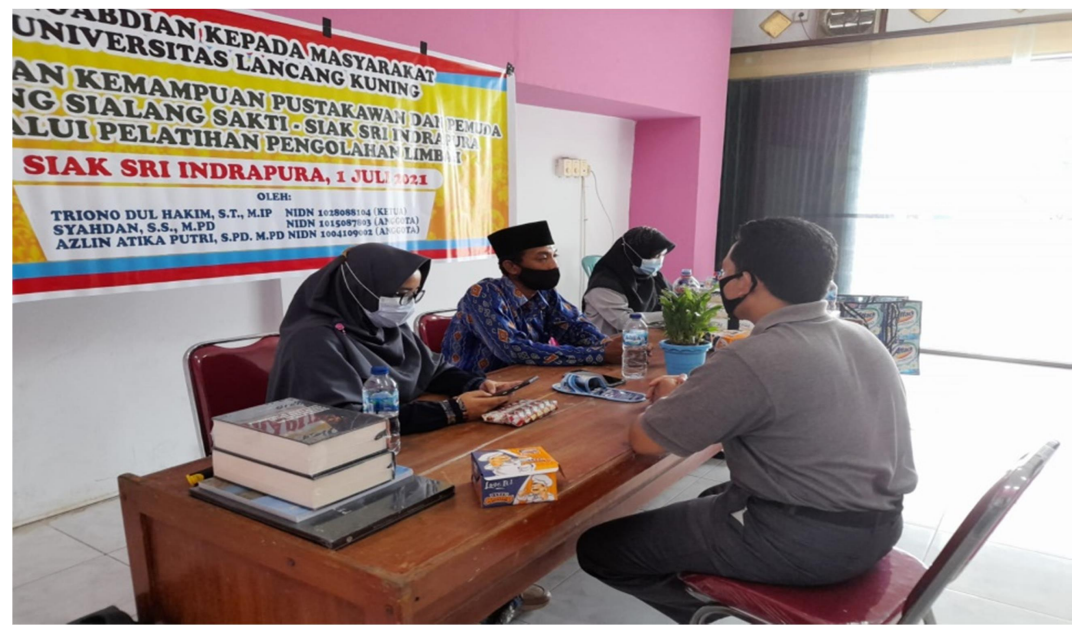

\section{Refleksi Capaian Program Pengabdian}

Kegiatan pengabdian berjalan dengan lancar, dan masyarakat mendapatkan manfaat, dapat dilihat dari hasil angket yang diberikan kepada peserta sebelum dan sesudah pelaksanaan kegiatan. Dari hasil ini membuktikan bahwa pemberdayaan masyarakat dengan basis potensi lokal akan bisa mendorong terbentuknya usaha kreatif (Susanto et al., 2021). Tabel 1 menunjukkan pemahaman peserta mengenai pengolahan limbah sebelum dan sesudah diberikan pelatihan.

Tabel 3. Reakpitulasi Hasil Pre-Test dan Post-Test

\begin{tabular}{|c|c|c|c|c|c|}
\hline \multirow{2}{*}{ No } & \multirow{2}{*}{ Pengolahan Limbah } & \multicolumn{2}{|r|}{ Pre } & \multicolumn{2}{|c|}{ Post Test } \\
\hline & & $\%$ & Kategori & $\%$ & Kategori \\
\hline 1 & $\begin{array}{l}\text { Apakah anda mengetahui apa itu } \\
\text { limbah }\end{array}$ & 57.85 & Cukup Baik & 74.28 & Baik \\
\hline 2 & $\begin{array}{l}\text { Bisakah anda membedakan } \\
\text { limbah organic dan limbah non } \\
\text { organik }\end{array}$ & 57.14 & Cukup Baik & 96.42 & Sangat Baik \\
\hline 3 & $\begin{array}{l}\text { Apakah anda pernah mengikuti } \\
\text { pelatihan pengolahan limbah } \\
\text { sebelumnya }\end{array}$ & 58.57 & Cukup Baik & 65 & Baik \\
\hline 4 & $\begin{array}{l}\text { Apakah anda tahu bagaimana } \\
\text { teknik pengolahan limbah secara } \\
\text { umum }\end{array}$ & 61.42 & Baik & 81 & Sangat Baik \\
\hline 5 & $\begin{array}{l}\text { Apakah anda pernah melihat } \\
\text { orang lain melakukan pengolahan } \\
\text { limbah }\end{array}$ & 61.43 & Baik & 77.85 & Baik \\
\hline 6 & Menurut anda apakah & 57.85 & Cukup Baik & 67.14 & Baik \\
\hline
\end{tabular}




\begin{tabular}{|c|l|c|c|c|c|}
\cline { 2 - 5 } \multicolumn{1}{|l}{} & $\begin{array}{l}\text { pengolahan limbah itu sesuatu } \\
\text { yang sulit dan memberatkan }\end{array}$ & & & & \\
\hline 7 & $\begin{array}{l}\text { Pernahkan anda mengikuti } \\
\text { pelatihan lain yang diadakan oleh } \\
\text { perpustakaan bina ilmu }\end{array}$ & 63.57 & Baik & 79.28 & Baik \\
\hline 8 & $\begin{array}{l}\text { Apakah kegiatan pelatihan ini } \\
\text { bermanfaat }\end{array}$ & 66.43 & Baik & 81 & Sangat Baik \\
\hline 9 & $\begin{array}{l}\text { Apakah anda akan } \\
\text { mengembangkan ilmu yang } \\
\text { didapat hari ini }\end{array}$ & 72.14 & Baik & 83.57 & Sangat Baik \\
\hline 10 & $\begin{array}{l}\text { Menurut anda apakah } \\
\text { pengolahan limbah ini memiliki } \\
\text { nilai ekonomis bagi anda }\end{array}$ & 68.57 & Baik & 81 & Sangat Baik \\
\hline & Rata-rata & $\mathbf{6 0 . 2 0}$ & $\begin{array}{c}\text { Cukup } \\
\text { Baik }\end{array}$ & $\mathbf{7 7 . 5 7}$ & Baik \\
\hline
\end{tabular}

\section{Penutup}

Kegiatan pengabdian berjalan dengan baik sesuai dengan target yang diharapkan. Peserta yang terdiri dari pustakawan dan pemuda mendapatkan pengetahuan tentang peran mereka dalam mengembangkan dan memberdayakan masyarakat dalam pemanfaatan limbah di sekitar, agar memiliki nilai ekonomi yang juga bermanfaat untuk lingkungan. Pelaksanaan kegiatan ini masih perlu dilanjutkan karena dapat menjadi wadah positif bagi pustakawan agar dapat meningkatkan tampilan estetika ruang perpustakaan dan keterampilan pemuda untuk menciptakan ekonomi kreatif, sehingga tujuan perpustakaan inklusi juga dapat tercapai. Adapun rekomendasi ke depan, pendampingan masyarakat berkelanjutan masih sangat diperlukan sehingga terjadi perubahan sosial di tengah masyarakat untuk lebih menjaga lingkungan dan mendapatkan manfaat ekonomi dari limbah rumah tangga.

\section{Daftar Pustaka}

Afni, Z., Sari, F. M., \& Prihati. (2021). Penguatan Kelembagaan Kampung Iklim Tobekgodang Kota Pekanbaru Terhadap Kebijakan Perubahan Iklim. Jurnal Masyarakat Mandiri, 5(4), 1597-1605.

Candrasari, Y. C., Dyva Claretta, \& Sumardjiajti. (2020). Pengembangan Dan Pendampingan Literasi Digital UntukPeningkatan Kualitas Remaja Dalam Menggunakan Internet. Dinamisia : Jurnal Pengabdian Kepada Masyarakat, 4(4). https://doi.org/10.31849/dinamisia.v4i4.4003

Indonesia, C. (2018). Riset: 24 Persen Sampah di Indonesia Masih Tak Terkelola. CNN Indonesia. https://www.cnnindonesia.com/gaya-hidup/20180425101643-282-293362/riset-24-persensampah-di-indonesia-masih-tak-terkelola 
Krisnawansyah, Y., Ediana, D., Fatma, F., Yuniliza, Y., Ekawandani, N., Faujiah, F., Rum, A. I., Mesin, T., Bandung, P. T., Darusmanl, H. Y., Mumu, H., Hamdan, A., Hugo Aries Suprapto, Muhammad Rusdi, P., Berdasarkan, S., No, U. U., Dpr, K., Ri, M. P. R., Gatot, J., Senayan, S., ... Tunggadewi, U. T. (2018). Partisipasi Masyarakat dalam Pengelolaan Sampah Reuse Reduce Recycle di Kabupaten Solok. Thesis, 1(2).

Mustaghfiroh, U., Ni'mah, L. K., Sundusiyah, A., Addahlawi, H. A., \& Hidayatullah, A. F. (2020). Implementasi Prinsip Good Environmental Governance dalam Pengelolaan Sampah di Indonesia. Bina Hukum Lingkungan, 4(2). https://doi.org/10.24970/bhl.v4i2.106

Prasyesti, M. (2021). Peningkatan Kemampuan Manajemen Perpustakaan Berbasis Inklusi Sosial pada Pengelola Perpustakaan Desa di Ponorogo. BIDIK: Jurnal Pengabdian Kepada Masyarakat, 1(2). https://doi.org/10.31849/bidik.v1i2.5702

Susanto, B., Pradana, F. S. A., Fitriana, R., Wulandari, N., Dina, F. A., \& Galih, S. S. (2021). Pemberdayaan Masyarakat Berbasis Potensi Lokal Menjadi Usaha Kreatif di Desa Duren. Community Empowerment, 6(3). https://doi.org/10.31603/ce.4305 